\title{
Maintenance Practice and Occupant's Satisfaction in Public Housing Estates: An Osogbo, Nigeria Perspective
}

\author{
Ige V. O. ${ }^{1, *}$, Binuyo O. P. ${ }^{1} \&$ Jimoh D. A. ${ }^{2}$ \\ ${ }^{1}$ Department of Estate Management, Federal University of Technology, Akure, Nigeria \\ ${ }^{2}$ Department of Estate Management, Federal Polytechnic, Ado, Ekiti State, Nigeria \\ Corresponding Author: *voige @ futa.edu.ng
}

\begin{abstract}
The paper appraises the maintenance practice and residents' satisfaction of public housing estates in Osogbo, Nigeria with a view to encouraging best practices and adequate maintenance strategies in a proposition to preserving the existing housing stock and enhanced maintenance of public estates in the study area. One Hundred and Five (105) questionnaires were distributed among the residents of two (2) residential estates and 97 questionnaires were retrieved, representing 92.40\%. Opinion of the Estate Surveyors and Valuers was also sought on the factors affecting maintenance in public housing estate. Analysis was carried out through the use of mean, severity index, cross-tabulation and Chi-Square test of association. It was discovered that there is no statistically significant relationship between maintenance practice and public services alongside infrastructures in the estates. Although, there is a significant relationship between occupants' level of satisfaction with maintenance of public services and infrastructures; the Phi and Cramer's V tests revealed a very weak strength in the association. The paper therefore suggests an integrated maintenance approach for effective upkeep of public estates infrastructures and facilities.
\end{abstract}

Keywords: Estates, Maintenance Practice, Public Housing, Occupants, Satisfaction

\subsection{Introduction}

Housing is one of life's basic necessities which encapsulates shelter, physical and mental health, economic and social wellbeing. However, Ibem and Amole (2010) observed that several Nigerians are still living in poor housing conditions. Hence, in a bid to provide quality housing in Nigeria, there have been government involvements at all levels. This has often occasioned the mass housing estates construction, provision of site and services and other infrastructures in urban centres for all income groups among others (Akindele et al., 2014). This form of housing provision has been construed as public housing, as it emphasizes the role of the government and its agencies in facilitating housing provision.

In spite of the efforts and increase funding by the government, the state of housing maintenance and repair is far from satisfactory (Nor'Aini et. al, 2013). Jiboye (2004) had previously noted that public housing has been in a badly maintained condition in Nigeria. The culture of poor and lackadaisical attitude towards maintenance like an infection has eaten deep into the marrow of Nigeria. This is obvious from the way public houses are managed. Buildings are set up and anticipated to live their life span without a bit of maintenance strategy. The less satisfactory maintenance level in most public housing in the country has been attributed to lack of proper and adequate monitoring and the politically motivated bureaucracy of those responsible for the maintenance of facilities and infrastructure in public housing (Adejimi 1998). Little wonder why despite the theories and hypotheses postulated and propounded, maintenance problems remained adamantly unyielding and so unsolved.

Iyagba (2005) maintained that the general absence of maintenance culture in Nigeria as a nation is one of the greatest economic and social problems. According to Harding et al. (2007), successive governments are more interested in the provision of new housing units without recourse to regular 
maintenance of the existing ones as a more sustainable way of reducing housing deficit. In addition, there is usually poor implementation of National Housing Policy, inadequate funding, lack of continuity of projects upon change in government, insecurity and neglect of such projects (Jiboye, 2008). Therefore, Anele (2010) opined that Nigeria will continue to waste scarce financial resources on building new infrastructure which cannot be sustained if urgent steps are not taken to embrace good maintenance culture

In view of the forgoing, a number of studies have considered public housing. For instance, Adenuga et al. (2010) examined the need for effective maintenance practices in public buildings and reasons for neglect of maintenance responsibilities. Lack of maintenance culture, lack of maintenance knowledge, lack of emphasis on training, retraining and continuing education on effective maintenance by the establishment, indiscipline and ignorance on the part of users, absence of planned maintenance programme and reactive maintenance, complexity of design, non-involvement of maintenance team at design stage and inadequate funds for maintenance are found to be affecting maintenance of public building in Nigeria.

Similarly, Akindele et al, (2014) assessed the condition of housing, adequacy of housing facilities and residents' perception of housing satisfaction with public estates in Osogbo, Nigeria. Using weighed mean values, it was found that there is a general deficiency in infrastructure development and almost all the estates considered in the study lack basic facilities. The study however, did not consider maintenance of the estates and the strategy adopted, which is one of the drives for this study.

With this state of affair in mind, it is thoughtful to inquire into the satisfaction of the occupants of the Nigerian public housing estates. Residents' satisfaction is the positive or negative emotion exhibited by occupants with respect to their housing. Residents' satisfaction has yet been employed as a measure to examine the success of housing development projects. It has been a very significant tool to evaluate and improve the performance of government policies associated with housing. In that feedback and resident's views collected with regard to housing projects could be fed back into the future design process for improvement (Mohammad and Mohamed, 2012).

\subsection{Methodology}

\subsection{Study Area}

Osogbo is situated on latitude $7^{0} 46^{\prime} \mathrm{N}$ and longitude $4^{0} 34^{\prime} \mathrm{E}$ of Greenwich Meridian. It assumed the rank of a State capital subsequent the establishment of Osun State in 1991. Its population, based on 2006 census was 156,694 and the total land area was about $2,875 \mathrm{~km}^{2}$. Over the years, the city has witnessed remarkable growth both spatially and in population. In recent times, the location of Osogbo as a state capital coupled with other developmental factors has led to the influx of people from other towns and villages. Despite the increasing provision and availability of some basic infrastructures, the level and condition of these facilities are still very insufficient as a result of the speedy rate of urbanization and population growth observed in the town. The quality of housing amenities and infrastructures is largely poor and falls below the probable standard. Considerably, adequate housing consolidates not only the national development but also determines the health, security, sanitation and socio-cultural and physical wellbeing of the populace. Development in Osogbo is observed as one moves from the interior towards the outskirts while most of the business neighbourhoods are mixed with residential districts.

\subsection{Data collection Instrument}

The data used for the analysis in this study are primary data and were collected using questionnaires. Eighteen questionnaires out of the 20 questionnaires distributed to the occupants of G.R.A Osogbo were retrieved representing $90 \%$, while 79 out of the 85 questionnaires distributed to the occupants of the Federal housing Estate, Osogbo was retrieved, representing 92.94\%. On a general note, 97 out of the 105 total administered questionnaires on the target population were retrieved representing $92.40 \%$. Equally, $19(86.36 \%)$ out of the 22 questionnaires distributed to the Estate Surveyors and Valuers was 
retrieved. This suggests a great percentage of response, thus giving sound footing for further analysis. The questionnaire was designed using a Likert scale, where the options of the possible responses from the respondents were ranked. Likert scale Kristin according to (2004) consist of respondents responses to statements about the object, where responses fall into ordered categories.

To assess the condition of infrastructure and services in the Estates, a Likert scale that ranges from ' 1 ' $=\mathrm{Bad},{ }^{\prime} 2$ ' $=$ Average, ' 3 ' $=$ Good was used. For the condition of the infrastructure and services in the Estates, Mean Score above 1.50 are considered to be 'Good' while the Mean Score less than 1.50 are regarded as 'Bad'. Also, a Likert scale ranged from " 1 " = very dissatisfied, "2"=dissatisfied, " 3 "=slightly satisfied, "4"=satisfied and "5"=very satisfied, was used to measure respondents' level of satisfaction on various housing components. The overall satisfaction for each feature of residential satisfaction was analysed based on a mean score of 3.00 as positive indication of satisfaction, and values below 3.00 indicating dissatisfaction. While factors affecting maintenance in public housing estate was evaluated using severity index, further analysis was carried out using cross tabulation and Pearson's chisquare test (chi-square test of association) on statistical Package for Social Sciences (SPSS).

\subsection{Method of Data Analysis}

\section{i. Weighted Mean Score}

Weighted Mean score as explained by Abunab et al. (2016) was adopted to analyse the condition of infrastructure and services and the overall level of residents' satisfaction.

For the condition of the infrastructure and services, the Weighted Mean Score is given as:

$W M S=\frac{3 n_{3}+2 n_{2}+n_{1}}{n_{3}+n_{2}+n_{1}}$

Where $\mathrm{n}_{3}=$ number of responses for "Good", $\mathrm{n}_{2}=$ number of responses for "Average", $\mathrm{n}_{1}=$ number of responses for "Bad".

For the overall level of residents' satisfaction, the Weighted Mean Score is given as Weighted Mean Score (WMS) is determined using Equation (2).

$W M S=\frac{5 n_{5}+4 n_{4}+3 n_{3}+2 n_{2}+n_{1}}{n_{5}+n_{4}+n_{3}+n_{2}+n_{1}}$

Where $\mathrm{n}_{5}=$ number of responses for "Very Satisfied", $\mathrm{n}_{4}=$ number of responses for "Satisfied", $\mathrm{n}_{3}=$ number of responses for "Slightly Satisfied", $\mathrm{n}_{2}=$ number of responses for "Dissatisfied", $\mathrm{n}_{1}=$ number of responses for "Very dissatisfied".

\section{ii. Chi-Square Test of Association}

The Chi-Square test of association is used to discover if there is a relationship between two or more categorical variables measured at an ordinal or nominal scale. This test gives evidence of an association or no association (Pandis, 2016). This was used in this study to test the relationship between the observed and expected level of maintenance of public infrastructure in the estates. It was also used to test for the relationship between the observed and expected level of satisfaction of residents with the maintenance of public services and infrastructure.

Chi-square is given as:

$\chi_{c}^{2}=\sum\left(\frac{\left(E_{i}-O_{i}\right)^{2}}{E_{i}}\right)$

Where,

The subscript "c" = the degrees of freedom

$\mathrm{E}_{\mathrm{i}}=$ the Expected value; and

$\mathrm{O}=$ the Observed value.

\section{iii. Severity Index}

Mathematically, severity index according to Kadir et al (2005) is given as: 
Severity Index $(S I)=\frac{\sum \mathrm{R}_{\mathrm{w}} \mathrm{w}}{R_{t}}$

Where,

$\mathrm{R}_{\mathrm{w}}=$ number of respondents;

$\mathrm{W}=$ weight or points assigned; and

$R_{t}=$ total number of responses obtained from that variable. The scale depicting the degree of severity is interpreted as follows:

S.I $\leq 1.4$ implies not serious, not difficult or never felt its effect

S.I $=1.5-3.4$ implies moderately serious or difficult or felt its effect some of the time

S.I $=2.5-4.4$ implies usually serious, usually difficult or felt its effect many times

S.I $\geq 4.5$ implies very serious, very difficult or felt its effect most of the time.

\subsection{Results and Discussion}

The analysis of the data obtained through the questionnaire was carried out using descriptive analysis. Descriptive analysis featured the use of simple frequency distribution table, weighted mean score and Pearson's chi-square test.

Table 1: Condition of infrastructures and facilities

\begin{tabular}{lcccc}
\hline \multirow{2}{*}{ Infrastructures and facilities } & \multicolumn{2}{c}{ Occupants of G.R.A } & \multicolumn{2}{c}{$\begin{array}{c}\text { Occupants of Federal } \\
\text { Housing Estate }\end{array}$} \\
\cline { 2 - 5 } & Mean & Rank & Mean & Rank \\
\hline Water supply & 2.78 & $1 \mathrm{st}$ & 2.89 & $1 \mathrm{st}$ \\
Refuse Collection & 1.78 & 13 th & 2.11 & 12 th \\
Sewage Disposal System & 2.39 & 8 th & 2.87 & 2 nd \\
Drainage & 2.17 & 9 th & 2.72 & 3 rd \\
Road Network & 2.17 & 9 th & 2.50 & 5 th \\
Schools and educational centers & 2.61 & $3 \mathrm{rd}$ & 2.06 & 13 th \\
Health facilities & 2.56 & 5 th & 2.42 & 8 th \\
Commercial center & 1.83 & 12 th & 2.48 & 6 th \\
Recreational centers & 2.17 & 9 th & 2.39 & 9 th \\
Firefighting equipment & 2.56 & 5 th & 2.43 & 7 th \\
Electricity & 2.61 & $3 \mathrm{rd}$ & 2.17 & 11 th \\
Telecommunication infrastructure & 2.44 & 7 th & 2.32 & 10 th \\
Security services & 2.67 & $2 \mathrm{nd}$ & 2.53 & 4 th \\
\hline
\end{tabular}

Table 1 shows the assessment of the condition of infrastructural facilities available in the estates. From the G.R.A., the condition of water supply with mean score of 2.78 and security services with a mean score of 2.67 is good and has been ranked 1st and 2nd respectively. The least / relatively in a fair state is refuse collection with a mean score of 1.78 and has been ranked 13th. The occupants of Federal Housing Estate also rated water supply to be in a very good condition with a mean score of 2.89 and ranked 1st, this is closely associated with the good condition of sewage disposal and drainage with the mean scores of 2.87 and 2.72, and ranked 2nd and 3rd respectively. However, all the infrastructures and facilities identified were found to be in at least an average condition, as their Mean Score were all above 1.5 , this results show an improvement on the condition of infrastructure in the study area when compared with the results of Akindele et al, (2014) who had earlier found a poor condition of infrastructures in the study area. However, the condition of the school and educational ranked lowest. This is not unrelated to the poorly maintained physical condition of the infrastructures of the schools educational centres as at the time of the analysis of this study. Equally, Kehinde et al. (2015) found that public estates in the entire study area were poorly equipped with infrastructure.

Table 2: Level of Satisfaction with specific building components

\begin{tabular}{lcccc}
\hline \multirow{2}{*}{ Specific Building Components } & \multicolumn{2}{c}{ Occupants } & of G.R.A & \multicolumn{2}{c}{ Occupants } & of Federal Housing Estate \\
\cline { 2 - 5 } & Mean & Rank & Mean & Rank \\
\hline Doors & 3.83 & $4^{\text {th }}$ & 3.44 & 6 th \\
Windows & 3.50 & $6^{\text {th }}$ & 3.85 & 4 th \\
Roof & 4.00 & $2^{\text {nd }}$ & 4.03 & 2 nd \\
Internal Wall & 3.61 & $5^{\text {th }}$ & 4.18 & 1 st \\
Beams and columns & 4.00 & $2^{\text {nd }}$ & 3.75 & 5 th \\
External walls & 4.11 & $1^{\text {st }}$ & 3.99 & 3 rd \\
Finishing & 3.22 & $7^{\text {th }}$ & 2.81 & 7 th \\
\hline
\end{tabular}


The level of satisfaction with some specific building components was also assessed and presented in Table 2. The results have been ranked accordingly for better understanding. G.R.A occupants were found to be satisfied with the 'external walls' with a mean score of 4.11 , which ranked $1^{\text {st }}$ while the occupants of Federal Housing considered the 'Internal walls' most satisfactory on their list with a mean

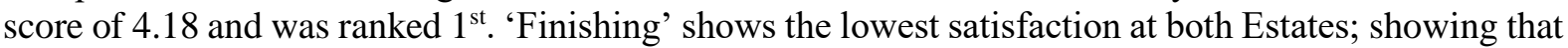
the level of satisfaction derived by the occupants of both Estates on the Finishing of the building is low. These results show that there are differences in the level of satisfaction of the resident on the identified building components in both estates. The level of satisfaction of the residents to the roof at both estates ranked second with a mean score that were above 2.5. This explains the uniqueness of different estates and the difference in the value of their land and landed properties. It could be from the law guiding the development of each estate or the ownership which control the type and nature of development.

Table 3: Level of Satisfaction with the available infrastructures and facilities in the Estates

\begin{tabular}{|c|c|c|c|c|}
\hline \multirow{2}{*}{ Infrastructures and facilities } & \multicolumn{2}{|c|}{ Occupants of G.R.A } & \multicolumn{2}{|c|}{$\begin{array}{c}\text { Occupants of Federal Housing } \\
\text { Estate }\end{array}$} \\
\hline & Mean & Rank & Mean & Rank \\
\hline Water supply & 4.22 & $1 \mathrm{st}$ & 3.84 & 2 nd \\
\hline Refuse Collection & 2.22 & 11 th & 2.73 & 10th \\
\hline Sewage Disposal System & 4.17 & 2nd & 3.62 & 5 th \\
\hline Drainage & 3.72 & $3 \mathrm{rd}$ & 3.41 & 6th \\
\hline Road Network & 3.72 & $3 \mathrm{rd}$ & 3.73 & 4th \\
\hline Schools and educational centers & 3.56 & 5 th & 3.08 & 7 th \\
\hline Health facilities & 2.50 & 10th & 2.58 & 12 th \\
\hline Commercial center & 2.83 & 7 th & 2.91 & 8th \\
\hline Recreational centers & 1.89 & 13th & 2.58 & 12 th \\
\hline Firefighting equipment & 2.83 & 7 th & 2.67 & 11th \\
\hline Electricity & 2.22 & 11 th & 3.75 & $3 \mathrm{rd}$ \\
\hline Telecommunication infrastructure & 3.11 & 6 th & 2.87 & 9th \\
\hline Security services & 2.72 & 9th & 3.94 & $1 \mathrm{st}$ \\
\hline
\end{tabular}

The respondent's level of satisfaction with the infrastructures is presented in Table 3. The occupants of G.R.A. are more satisfied with water which has the highest mean score of 4.22 and has been ranked $1^{\text {st }}$. This is closely followed by 'sewage disposal', 'Road network and drainage' with mean scores of 4.17 and 3.72 ranked 2nd and 3rd respectively. The least satisfied is recreational centre which is ranked 13th. On the other hand, occupants of the Federal Housing estate consented to the high level of satisfaction with security with a mean score of 3.94. This is closely followed by water supply and electricity with mean scores of 3.84 and 3.75, and ranked 2nd and 3rd respectively. The least satisfied are health and recreational which ranked 12th each. Nevertheless, there were difference in the satisfaction with infrastructure and facilities and their condition when compared Tables 1 and 3 . One of the infrastructures and facilities had increase in their rank at the level of satisfaction while others had decrease in their level of satisfaction at both estates. Only water supply maintained the first position of it condition and the level of satisfaction derived from it by the resident at the G.R.A. At both estate, infrastructure such and facilities such a refuse collection, sewage disposal, and telecommunication infrastructure had an increase in their rank at the level of satisfaction, while the health facilities had a drop in rank at both estate. Infrastructures and facilities that had an increase in rank at the level of satisfaction derived from them as compared to their condition imply that though their condition are not as good as other infrastructure and facilities that are ranked higher, the resident derived more satisfaction from them. Also, the infrastructures that had a higher rank in their condition than their rank at the level of satisfaction, imply that it is possible that an infrastructure or facilities may be in a good condition, it does not translate to serving it purpose as expected. The Health facilities for instance could be in a better condition than Electricity at Federal Housing Estate, it however does not satisfy the desire of the resident as electricity does at the estate. 
Table 4: Cross tabulation of the level of maintenance of public services and infrastructures in the Estates

\begin{tabular}{|c|c|c|c|c|c|c|}
\hline & & & \multicolumn{3}{|c|}{ Level of Maintenance } & \multirow{2}{*}{ Total } \\
\hline & & & Poor & Fair & Good & \\
\hline \multirow{4}{*}{ Respondents } & \multirow[b]{2}{*}{ Federal Housing Estate } & Count & 18 & 44 & 17 & 79 \\
\hline & & $\begin{array}{c}\% \text { within } \\
\text { Respondents }\end{array}$ & $22.8 \%$ & $55.7 \%$ & $21.5 \%$ & $100.0 \%$ \\
\hline & \multirow[b]{2}{*}{$\begin{array}{c}\text { Government Reserved } \\
\text { Area (GRA) }\end{array}$} & Count & 2 & 7 & 9 & 18 \\
\hline & & $\begin{array}{c}\% \text { within } \\
\text { Respondents }\end{array}$ & $11.1 \%$ & $38.9 \%$ & $50.0 \%$ & $100.0 \%$ \\
\hline
\end{tabular}

Table 4 gives insight into the respondent's opinion of the level of maintenance of public services and infrastructures at both estates. The result of the table shows that the majority of the respondent at the Federal Housing Estate believed that the estate is fairly managed at $55.7 \%$ while the majority of the respondent at the GRA responded that the level of maintenance of the estates is good. However, at both estates, poor level of maintenance has the least percentage of response. This implies that the maintenance of the estates are between fair and good.

Table 5: Chi-Square Tests of association of the maintenance of public services and infrastructures in the Estates

\begin{tabular}{lcccc}
\hline & Value & Df & Asymp. Sig. (2-sided) & Approx. Sig. \\
\hline Pearson Chi-Square & 6.193 & 2 & 0.045 & 0.057 \\
Likelihood Ratio & 5.728 & 2 & 0.026 & \\
Linear-by-Linear Association & 4.973 & 1 & & \\
N of Valid Cases & 97 & & & \\
\hline
\end{tabular}

Table 5, shows that the critical value of chi-square $\chi^{2}=6.193$ is greater than the observed value of chisquare $\mathrm{p}=0.045(\mathrm{p}<0.05)$. This suggests that there is no statistically significant difference between the opinion of respondents of both estates on the maintenance of public services and infrastructures. Hence, it is evident that the level of maintenance of public services and infrastructures is not differ from one public estate to another. This may be corroboration of poor building maintenance habits earlier identified by Quayson and Akomah (2016) and Twumasi-Ampofo et al. (2017) as being prevalent in public buildings.

Table 6: Cross tabulation of the level of satisfaction with maintenance of public services and infrastructures

\begin{tabular}{|c|c|c|c|c|c|c|}
\hline & & & \multicolumn{3}{|c|}{$\begin{array}{l}\text { Quality of the services and } \\
\text { infrastructures }\end{array}$} & \multirow[t]{2}{*}{ Total } \\
\hline & & & $\mathrm{N} \mathrm{S}$ & LS & $\mathrm{S}$ & \\
\hline \multirow{4}{*}{ Respondents } & \multirow{2}{*}{$\begin{array}{l}\text { Federal Housing } \\
\text { Estate }\end{array}$} & Count & 22 & 9 & 48 & 79 \\
\hline & & $\begin{array}{c}\% \text { within } \\
\text { Respondents }\end{array}$ & $27.8 \%$ & $11.4 \%$ & $60.8 \%$ & $100.0 \%$ \\
\hline & \multirow{2}{*}{$\begin{array}{c}\text { Government Reserved } \\
\text { Area (GRA) }\end{array}$} & Count & 4 & 2 & 12 & 18 \\
\hline & & $\begin{array}{c}\% \text { within } \\
\text { Respondents }\end{array}$ & $22.2 \%$ & $11.1 \%$ & $66.7 \%$ & $100.0 \%$ \\
\hline
\end{tabular}

Table 6 gives the clear understanding of the respondent's opinion on the level of satisfaction with maintenance of public services and infrastructures. The level of maintenance in relation to the satisfactory nature of the quality of services and infrastructure shows that majority of the respondents are satisfied with the quality of services at $60.8 \%$ and $66.7 \%$ at the Federal Housing Estate and G.R.A. respectively. However, $22.2 \%$ and $27.8 \%$ of the residents of G.R.A and Federal Housing Estate respectively are not satisfied with the quality of services and infrastructures provided in the estates. This clearly indicates the need for an efficient maintenance programme so as to improve the satisfaction of the occupants. 
Table 7: Chi-Square Tests of association of the occupants' level of satisfaction with maintenance of public services and infrastructures

\begin{tabular}{lcccc}
\hline & Value & df & Asymp. Sig. (2 sided) & Approx. Sig. \\
\hline Pearson Chi-Square & .257 & 2 & 0.879 & \\
Likelihood Ratio & .264 & 2 & 0.877 & \\
Linear-by-Linear Association & .253 & 1 & 0.615 & \\
Phi & .051 & & & 0.879 \\
Cramer's V & .051 & & & 0.879 \\
N of Valid Cases & 97 & & & \\
\hline
\end{tabular}

Table 7 shows that the critical value of chi-square $\chi 2=0.257$ which was lesser than the observed value of chi-square $p=0.897$. This implies a statistically significant association in the opinion of the occupants of the Estates' on the level of satisfaction with maintenance of public services and infrastructures. Nevertheless, the chi square test does not tell the strength of association. According to Malhotra (2009), strength of association is of interest when the association is statistically significant. The strength of association can be measured by phi correlation coefficient and Cramers V. The Cramer's $\mathrm{V}$ value varies between 0 to +1 . If it takes the value of 0 , there is no association while +1 shows perfect positive association. A large value of $\mathrm{V}$ merely indicates a high degree of association, but does not indicate how the variables are associated. The strength of association through a Phi and Cramer's $\mathrm{V}$ test from the test revealed a very weak relationship $(\mathrm{Phi}=.051$ and Cramer's $\mathrm{V}=.051$ ) between occupants' and their level of satisfaction with maintenance of public services and infrastructures at both estates'. Kehinde (2015) et al. earlier established that public estates in Osogbo fell short of overall mean value measurement of residents' satisfaction.

Table 8: Source of infrastructure and facilities Maintenance

\begin{tabular}{lcccc}
\hline \multirow{2}{*}{ Source } & \multicolumn{2}{c}{ Occupants of G.R.A Osogbo } & \multicolumn{2}{c}{$\begin{array}{c}\text { Occupants of Federal Housing } \\
\text { Estate Osogbo }\end{array}$} \\
\cline { 2 - 5 } & Percent & Frequency & Percent & Frequency \\
\hline Development Levy & 4 & 22.2 & 8 & 10.1 \\
Joint Community Service & 5 & 27.8 & 38 & 48.1 \\
Through Government Efforts & 5 & 27.8 & 13 & 16.5 \\
Individual Efforts & 3 & 16.7 & 14 & 17.7 \\
Others & 1 & 5.6 & 6 & 7.6 \\
Total & 18 & 100.0 & 79 & 100.0 \\
\hline
\end{tabular}

Table 8 assesses the body majorly responsible for the maintenance of the infrastructures and amenities in the neighbourhood. The result shows that $27.8 \%$ of the respondents at G.R.A. indicated that maintenance of the infrastructure is done through Joint Community Service while $48.1 \%$ of the respondents at Federal Housing Estate also revealed that the maintenance of the infrastructure is done through Joint Community Service. At G.R.A. and Federal Housing Estate respectively, 27.8\% and $16.5 \%$ also confirm the involvement of the Osun State and its relative agencies in the maintenance of the infrastructures. The use of development levies was also identified by the study. On the other hand, some of the respondents also agreed to the combined role of residents association and the government agencies marked as 'others' for the maintenance of the estate services and infrastructures with the highest percentage at the Federal Housing estate representing 7.6\% and 5.6\% for G.R.A. 
Table 9: Factors affecting Maintenance in Public Housing Estate

\begin{tabular}{lcc}
\hline Mean & Severity Index (SI) & Rank \\
\hline Use of substandard of materials and building components & 4.1 & $1^{\text {st }}$ \\
Maintenance Culture & 4.0 & $2^{\text {nd }}$ \\
Availability of fund for maintenance of the building & 4.0 & $3^{\text {rd }}$ \\
Low concern to future maintenance & 3.9 & $4^{\text {th }}$ \\
Behaviour and attitude of occupants & 3.9 & $4^{\text {th }}$ \\
Lack of care/use of building components and services & 3.8 & $6^{\text {th }}$ \\
Lack of care/use of building components and services & 3.8 & $6^{\text {th }}$ \\
Clients attitude to maintenance & 3.7 & $8^{\text {th }}$ \\
Inadequate building maintenance standard and policy & 3.7 & $9^{\text {th }}$ \\
Workmanship during construction and maintenance & 3.6 & $10^{\text {th }}$ \\
Design affecting Resolution & 3.5 & $11^{\text {th }}$ \\
Improper selection of building material component and system & 3.4 & $12^{\text {th }}$ \\
Technological changes and fashion & 3.4 & $13^{\text {th }}$ \\
Availability of skilled maintenance personnel & 3.3 & $14^{\text {th }}$ \\
Ignorance about the basic properties of building materials and components & 3.3 & $15^{\text {th }}$ \\
Poor maintenance of maintenance group & 3.2 & $16^{\text {th }}$ \\
Non availability of replacement parts and components & 3.1 & $17^{\text {th }}$ \\
Use of new materials and components in building & 3.1 & $18^{\text {th }}$ \\
Lack of communication between maintenance contractors, clients and users & 2.8 & $19^{\text {th }}$ \\
Delay in occupancy after completion & 2.5 & $20^{\text {th }}$ \\
\hline
\end{tabular}

Table 9 analyses the respondents' opinion on the factors affecting building maintenance in public estates. The various factors were assessed, presented with SI and ranked for better meaning and interpretation to the study. The most ranked factors are the 'use of substandard of materials and building components' 'maintenance culture' and 'availability of fund for maintenance of the building' with the SI score of 4.1, 4.0 and 4.0 respectively. These factors fall within $2.5-4.4$ and implies that the factors are usually serious, usually difficult or its effect are felt many times. These factors and others that are highly ranked in this analysis corroborated the factors established in Adenuga et al., (2010) especially lack of maintenance culture, and low concern for future maintenance (absence of planned maintenance programme).

\subsection{Conclusion}

The study assessed the maintenance of public housing estates in Osogbo, Nigeria with a view to embracing best practices and adequate maintenance policies in an attempt to provide rational guide to make objective decision in preserving the present housing stock and further enhance maintenance of public estates in the study area. It has identified the various infrastructures available in the estates and analysed them in terms of their availability, condition and the relative satisfaction of the occupants with respect to the availability of the infrastructures. The level of satisfaction of the occupants to the general features of the buildings and infrastructures has also been considered. The analysis of this study show that though the condition of a facility or infrastructure may be better than other infrastructure, it might not be satisfactory in its level of utilization. Therefore, the provision of the facilities and infrastructure are not enough, the impact of their utilization is also to be given adequate attention. The results of this study therefore suggest that for maintenance of public infrastructure and facilities to be effective, there is the need for an integrated maintenance approach.

\section{References}

Abunab, H.Y., Dator, W.L.T., and Laoingco, J.R.C. (2016). Global Health Competencies of Nurse Students in Philippines. i-manager's Journal on Nursing, 6(2), 24-31. 
Adejimi, A. (2005). Poor Building Maintenance are Architects Free from Blames? A Paper presented at the ENHR International Conference on Housing: New Challenges and Innovations in Tomorrow's Cities. Iceland 2005.

Adenuga, O. A., Olufowobi, M. B. and Raheem, A. A. (2010). Effective Maintenance Policy as a Tool for Sustaining Housing Stock in Downturn Economy. Journal of Building Performance, 1(1), 93109.

Akindele, O. A., Ojo, T. and Abolade, O (2014) Perceived housing satisfaction in public estates of Osogbo, Nigeria. Academic journals, 7(9), 185-191.

Anele, D. (2010). Public Property, Maintenance Culture and the Nigerian. Nigeria: The Punch.

Harding, P., Rosental, S. and Sirmans, C. (2007). Depreciation of housing capital, maintenance, and house price inflation: Estimates from a repeat sales model. Journal of Urban Economics, 61(2), 193217.

Ibem, E.O and Amole, O.O. (2010) Evaluation of Public Housing Programmes in Nigeria: A Theoretical and Conceptual Approach. The Built and Human Environment, Review, 3: 88- 116

Iyagba, R.O.A. (2005). 'The menace of sick buildings: a challenge to all for its prevention and treatment', An Inaugural Lecture delivered at University of Lagos, Lagos.

Jiboye, A. D. (2004) An Assessment of the Influence of Socio-Cultural Factors on Housing Quality in Osogbo, Osun State, Nigeria, An unpublished M.Sc. Thesis, Department of Urban and Regional Planning, Obafemi Awolowo University, Ile-Ife.

Jiboye, A.D (2008). A Study of Public Housing Satisfaction in Lagos, Nigeria. Ph.D Thesis. Department of Urban and Regional Planning, Obafemi Awolowo University, Ile-Ife, Nigeria.

Kehinde O. J., Ojo, T. I. and Oginni, E. O. (2015). Residents' satisfaction in public estates in Osogbo, Nigeria. Merit Research Journal of Art, Social Science and Humanities, 3(1), 10-17.

Kristin, N. J. (2004). Analysis of Likert Data on Attitudes. PhD thesis, Balliol College University of Oxford.

Malhotra, N. K. (2009). Marketing Research: An Applied Orientation. 6th Edition, Prentice Hall.

Mohammad, A. M. and Mohamed, A. (2012). Assessment of Residential Satisfaction with Public Housing in Hulhumale', Maldives. Procedia - Social and Behavioural Sciences, 50 (2012), 756 770 .

Nor'Aini, Y., Nazirah, Z. A. Nurul and Ulyani, M. N. (2013) Performance of Housing Maintenance in Public Housing. Journal of Economics and Sustainable Development, 4(6), 156-163.

Pandis, N. (2016). The chi-square test. American Journal of Orthodontics and Dentofacial Orthopedics, 150(5), 898-899.

Twumasi-Ampofo, K., Ofori, P. A., Osei Tutu, E., Cobinah, R., Twumasi, E. A. and Kusi, S. (2017). Maintenance of Government Buildings in Ghana: The Case of Selected Public Residential Buildings in Ejisu-Ashanti. Journal of Emerging Trends in Economics and Management Sciences (JETEMS), 8(3):146-154.

Quayson, J. H. \& Ankomah, B. B. (2016). Maintenance of Residential Buildings of Selected Public Institutions in Ghana. African Journal of Applied Research, 3(3), 48-56. 